\title{
The Role of Maternal Depression on Treatment Outcome for Children with Externalizing Behavior Problems
}

\author{
Linda M. A. van Loon • Isabela Granic • \\ Rutger C. M. E. Engels
}

Published online: 21 April 2011

(C) The Author(s) 2011. This article is published with open access at Springerlink.com

\begin{abstract}
Studies have shown that, on average, Parent Management Training combined with cognitive-behavioral therapy decreases children's externalizing behavior, but some children do not improve through treatment. The current study aimed to examine the role of maternal depression in understanding this variability in treatment outcome. Children with externalizing behavioral problems and their parents were recruited from combined Parent Management Training and Cognitive-Behavioral programs in "real-world" clinical settings. At pre- and post treatment, maternal depression and children's externalizing behavior were assessed. Results showed that treatment was less effective for children of depressed mothers compared to non-depressed mothers and that improvements in maternal depression were associated with improvements in children's externalizing behavior. These findings suggest that treatment programs for children with externalizing problems may be able to improve outcomes if maternal depression is a target of intervention.
\end{abstract}

Keywords Maternal depression - Externalizing behaviour problems $\cdot$ Childhood $\cdot$ Combined treatment

\section{Introduction}

The prevalence of externalizing behavior problems (e.g., aggression, delinquency) is high; approximately half of children's mental health problems are for externalizing issues (Connor 2002; Patterson et al. 1993). Childhood

L. M. A. van Loon $(\varangle) \cdot$ I. Granic $\cdot$ R. C. M. E. Engels

Behavioural Science Institute, Radboud Universiteit Nijmegen,

P.O. Box 9104, 6500 HE Nijmegen, The Netherlands

e-mail: 1.vanloon@psych.ru.nl aggression and delinquency predicts several adverse consequences later in life, such as adult criminality (e.g., Huesmann et al. 2002) and substance abuse (e.g., Fergusson et al. 2007). Clearly, effective interventions for this high-risk population are critical.

One of the most effective treatments for children with externalizing behavior problems is family-based Parent Management Training (PMT) with or without childfocused cognitive behavioral therapy (CBT) (Eyberg et al. 2008; Kazdin 2005). In PMT, social learning principles are used to decrease deviant behaviors and to increase prosocial, positive behaviors (Moore and Patterson 2009). The treatment model grew, in part, from Patterson and colleagues' applied observational research (Forgatch 1984; Patterson 1982; Patterson et al. 1992). Ample research has revealed that there is a clear link between poor parent-child relations and externalizing behavior in childhood (e.g., Dumas and LaFreniere 1993; Snyder and Patterson 1995) and that changing these coercive parenting practices significantly affects child functioning (Forgatch 1991). Combining Parent Management Training with childfocused CBT is another evidence-based strategy for improving children's problem behavior. Children with externalizing problems often misunderstand social cues and have difficulty regulating their resulting emotions. CBT targets externalizing behaviors and cognitions through techniques such as behavior management, role-playing, modeling, problem-solving, cognitive restructuring, and social reinforcements (Barkley 2000; Bloomquist and Schnell 2002). Several studies documented the effectiveness of combined PMT and CBT interventions for children with externalizing problems (e.g., Chambless and Ollendick 2000; McCart et al. 2006).

Despite evidence for the effectiveness of this treatment approach, not all families show improvements. It is not 
clear yet why some children show improvement in their externalizing behavior after the training, while others do not improve. Although it is already known that externalizing children are heterogeneous (e.g., Pardini et al. 2006), there could also be variability among parents as well. Particularly for parenting-focused treatments, it is important to identify parental characteristics that contribute to outcomes. One such promising parental factor is maternal depression.

Maternal depression has a large influence on child health and well-being (Kahn et al. 2004), and the association between maternal depression and child problem behavior has been widely documented (Barry et al. 2009; Beardslee et al. 1998; Cummings et al. 2008; Gelfand and Teti 1990; Hirshfeld-Becker et al. 2008). The emotional functioning of parents directly affects children's emotional, behavioral, and social functioning (Weissman et al. 2006). Children of depressed parents are at increased risk for both externalizing (Kim-Cohen et al. 2005) and internalizing problems (Wickramaratne and Weissman 1998). Parenting is one of the mechanisms by which parental depressive symptoms are thought to impact on children's treatment outcomes (Goodman and Gotlib 1999). The expression of depressive symptoms often has deleterious effects on parenting behaviors (Lovejoy et al. 2000). Depressed mothers exhibit more dysphoric and less happy affect (Jacob and Johnson 2001), are less attentive towards their children (Gelfand and Teti 1990), provide less consistency and structure (Goodman and Brumley 1990), have pessimistic perceptions about themselves (Teti and Gelfand 1997), and exhibit harsh judgments of their children (Caughy et al. 2009). As a result, depressed mothers are more negative and less positive during interactions with their children compared to nondepressed mothers (e.g., Foster et al. 2008). Moreover, maladaptive parenting practices relate to maternal depression and mediate, at least partially, the association between maternal depressive symptoms and child maladjustment (Bifulco et al. 2002; Burt et al. 2005; Johnson et al. 2001).

It is already known that maternal depression can influence the emergence and maintenance of externalizing behavior in children (Elgar et al. 2004; Goodman and Gotlib 1999). In turn, it may be that when maternal depression decreases, children's problem behavior also improves. To examine the relation between maternal depression and treatment outcomes for externalizing children, two objectives were addressed in the current study: (1) to examine whether initial levels of maternal depression before treatment begins predict treatment outcomes and (2) to study the association between changes in maternal depression and changes in children's levels of problem behavior.

Parents and children were assessed before and after their participation in a PMT/CBT combined program delivered in a community setting. We hypothesized that PMT would be less effective for children of depressed mothers than for children of non-depressed mothers. In addition, we expected that children of mothers whose depression improved from pre- to post-treatment would show a significantly larger decrease in their externalizing behavior compared to children of mothers whose depression did not improve.

\section{Method}

\section{Participants}

Parents and children were recruited from two children's community mental health agencies that offered the same combination of Parent Management Training (PMT) and Cognitive Behavioral Therapy (CBT) as treatment for children with externalizing problems and their families. At the intake stage of these treatment programs, the parents were asked if they were willing to speak to a research assistant to gain more information about the study. If the families agreed, the study was explained and the parent and child were asked if they were willing to participate. Assessments were conducted in either the clinical agency or at a university (whichever was easiest for parents to access) and families were offered $\$ 10.00$ at pre-treatment and \$20 at post-treatment. One hundred and four of the 145 families who were approached to participate consented. The most common reason that parents gave for refusing to participate was that they were too busy in their daily lives. The second most common reason was that their child refused to be involved. Because families who refused to participate in our research, by definition, did not consent to share information about themselves, we did not have the data to compare refusers with participants in the current study.

We began with 104 children and their mothers, referred by a mental health professional, teacher, or parent. To be included in the study, children had to score within the clinical range (98th percentile) on the Externalizing subscale of the Child Behavior Checklist (CBCL; Achenbach 1991a) and the mothers had to have filled in the Beck Depression Inventory II (BDI-II; Beck et al. 1996). Three families did not have a score on the CBCL and BDI-II (both pre and post), and were therefore omitted from further analyses. Thirty-one families did not have a score on both pre and post treatment on the CBCL or BDI-II. To solve this high degree of attrition and increase the internal validity of the current study we used Multiple Imputation (MI; i.e., Rubin 2004) to impute missing values, leaving a total sample of 101 families ( 86 boys and 15 girls) families. The children ranged in age from 7 to 12 years $(M=9.27, \mathrm{SD}=1.23)$. Mothers and children needed to have sufficient command of the English language to complete questionnaires without an interpreter. The child had to be currently living with the 
mother. Exclusion criteria included significant developmental delay and living outside of the catchment area of the community agencies.

Twenty-six percent of the children resided in intact families, $42 \%$ in single-parent (exclusively maternal) households, $21 \%$ in blended families, and $11 \%$ in other family configurations (e.g., grandparents). Based on parent identified ethnicity, $82 \%$ of the children were European (Caucasian), $12 \%$ were African or Caribbean, $1 \%$ was Asian, $1 \%$ was Latin-American, and $4 \%$ were of mixed backgrounds. In terms of family income, $19 \%$ made under $\$ 20,000$ per year, $23 \%$ made between $\$ 20,000$ and $\$ 39,000,25 \%$ made $\$ 40,000$ to $\$ 60,000$, and $33 \%$ made over $\$ 60,000$.

\section{Intervention}

The treatment program was an evidence-based intervention for children between 6 and 12 years of age and their parents. The program is called SNAPTM (Stop Now and Plan; Earlscourt Child and Family Centre 2001a, b; Goldberg and Leggett 1990) and it combines PMT and CBT. The clinical directors of the program have been consulting with the original developer of PMT (Marion Forgatch at the Oregon Social Learning Center) for over 15 years to ensure fidelity to the original treatment model. Therapists were either social workers, child-care workers or M.A. or Ph.D.level clinical psychology students. Like most social welfare programs in Canada, families were not charged for treatment services. The program was delivered to both parents (PMT) and children (CBT) once a week for 14 weeks in a group format. The groups met for $3 \mathrm{~h}$ during the evening at the community agencies. In the PMT groups, parents were taught to replace coercive or lax discipline strategies with mild sanctions (e.g., time-out) that contingently target misbehavior (Forehand 1986). The groups also promoted positive parenting practices such as skill encouragement (e.g., providing contingent praise for success, prompting for appropriate behavior), problem-solving, angermanagement techniques and monitoring instructions (Forgatch and Degarmo 1999; Martinez and Forgatch 2001). In the CBT groups, aggressive and delinquent behaviors and negatively-biased cognitions were targeted for change through well-documented strategies such as behavior management, role-playing, problem-solving, cognitive restructuring, social and token reinforcements, and generalization activities (Barkley 2000; Bloomquist and Schnell 2002).

\section{Measures}

Parental Report of Externalizing Behavior Parental ratings of child problems were obtained from the CBCL (Achenbach 1991a). The CBCL consists of 113 items and assesses multiple problem areas on a 3-point scale (i.e., $1=$ not true, $2=$ somewhat true, $3=$ very true). Parents were asked to rate their child's behavior for the month prior to the start of treatment and again for the month after the group ended. The CBCL is a standardized, highly reliable and valid measure of children's emotional and behavioral problems and yields a standardized T-score for Externalizing Problems.

Parental Depressive Symptoms Parental depressive symptomatology was obtained from the Beck Depression Inventory II (Beck et al. 1996). The BDI-II consists of 21 items which assess symptoms (e.g., change in appetite) and attitudes (e.g., pessimism) rated from 0 to 3 in terms of intensity. This instrument has high internal and content validity, is sensitive to changes, and shows high validity in differentiating between depressed and non-depressed people (Richter et al. 1998). A review of this inventory showed a consistent relationship between self-reported BDI scores and clinician's perceptions (Beck et al. 1988). In the present study, a reliable composite depressive symptoms score was computed by averaging the 21 items for both pre- ( $M=$ $14.08)$ and post-treatment $(M=9.76)$. Scores below 10 on the BDI-II represent the non-clinical range (minimal or no depression) and scores above 10 place people in the clinical range (mildly to severely depressed).

\section{Procedure}

Data were obtained before the start and after the completion of the 14-week treatment program. Parents were asked by clinic personnel to complete measures of the child's emotional and behavioral functioning. Beginning the week before treatment started and after the treatment ended, the parent completed the Beck Depression Inventory II (BDI-II).

\section{Results}

Preliminary Analysis

We used a multiple imputation procedure (MI; Rubin 2004) to analyze patterns of missing values in order to minimize the impact of missing data. Multiple imputation refers to randomly imputing missing values, in which you repeat this procedure several times to get several datasets, and carry out the analyses for each dataset and combine these results. We imputed the original dataset 10 times in SPSS, and we used the complete datasets with the multiple imputed values to analyze the data. The pooled means are reported and the averaged standard deviations. 
The pooled means and averaged standard deviations of the main variables by measurement point, with and without multiple imputation, are presented in Table 1. A paired $t$ test was conducted for each variable and Cohen's $d$ was computed. Depressed mothers showed a significantly lower mean depression score at post-treatment $(M=9.76, S D=$ 9.76) compared to pre-treatment $(M=14.08, S D=9.48)$. Children's externalizing behavior also decreased significantly over time (Pre-treatment: $M=72.69, S D=6.55$; Posttreatment: $M=67.02, S D=10.22$ ). The size of these effects was moderate (i.e., respectively .45, .64).

Table 2 presents the pooled correlations among the main variables by measurement point. As expected, the stability of depression and externalizing behavior was strong. Correlations showed that pre- and post-treatment measures of depression and pre- and post-measures of externalizing behavior were significantly correlated. Maternal depression and child externalizing behavior were significantly correlated at pre- and post-treatment.

\section{The Association between Maternal Depression} and Treatment Outcome

To test our first hypothesis that mothers who were depressed at pre-treatment would be less likely to benefit from treatment than children of non-depressed mothers, a repeated measures ANOVA was used to examine changes in externalizing behavior over time, with pre-treatment CBCL externalizing scores as the first factor, post-treatment CBCL externalizing scores as the second factor, and the depression status of the mother as the between-subject factor. Results showed that children of non-depressed mothers improved significantly more in their externalizing behavior (Pre: $M=70.34, S D=6.42$; Post: $M=61.66$, $S D=11.87$ ) than children of depressed mothers (Pre: $M=$ 73.88, $S D=6.31$; Post: $M=69.49, S D=8.90, F(1,99)=$ $9.24, p<.05)$. Figure 1 presents the changes from pre- to post-treatment on externalizing scores for children of depressed and non-depressed mothers separately. Although both children of non-depressed and depressed mothers showed a decrease in their externalizing behavior, it is important to note that children of depressed mothers remained above the borderline clinical cutoff ( $>67$; Achenbach 1991) of externalizing problems $(M=69.49, S E=1.31)$ at posttreatment, indicating that these children remained significantly impaired by the end of treatment. In contrast, children of non-depressed mothers fell below the borderline clinical cutoff $(M=61.66, S E=2.29)$ by the end of treatment. A $t$-test revealed that this difference in posttreatment scores on externalizing behavior was significant $t(92.67)=-3.04, p<.01$.

In addition to the repeated measures ANOVA, we used a dimensional approach as well, using a Linear Regression model with the continuous score on the BDI-II (see Table 3 for the pooled results with averaged Betas). Although results were in the predicted direction, using the continuous measure of the BDI-II did not yield significant findings.

Improvement of Maternal Depression Status

To address the second hypothesis that children of mothers whose depression improved with treatment would show a decrease in their externalizing behavior, mothers were classified as "Improvers" (IMPs), "Nonimprovers" (NIMPs) or "Nondepressed" (NDEPs) based on information from the BDI-II. Mothers who scored 10 or below 10 were considered non-depressed (minimal or no depression, based on BDI-II classifications); those who scored above 10 were considered depressed (mildly to severely depressed based on BDI-II classifications). Clinically significant improvement was operationalized as moving from depressed to non-depressed at post-treatment independently of the extent of the depression. ${ }^{1}$ Based on these criteria, 28 mothers were classified as improved (IMP; mothers were depressed at pretreatment and not depressed at post-treatment), 37 as nonimproved (NIMP; mothers were depressed at both pre- and post-treatment) and 36 were classified as NDEP (not depressed at pre- or post-treatment). We ran a repeated measure ANOVA to examine changes on children's externalizing behavior from pre- to post-treatment. The results showed that the externalizing behavior of the child was not significantly affected by the depression status of the mother, $F(2,99)=3.82$ (averaged), $p=.23$ (averaged $p$-value of the imputed datasets). Of the ten imputed datasets, four showed a $p$-value lower than .01 , one $p<.05$, two $p<.10$ and three p-values were $>.10$. As depicted in Fig. 2, children of NDEPs showed the largest improvement in externalizing behavior over the course of treatment, followed by children of IMPs and NIMPs. The children of the depressed improved mothers and the depressed nonimproved mothers both had a mean score above the borderline clinical cutoff ( $>67$, Achenbach, 1991) over the course of treatment (IMPs: $M=67.98$; NIMPs: $M=$ 69.52).

\section{Discussion}

The main objective of this study was to investigate the role of maternal depression on treatment outcome for children with externalizing behavior problems. We hypothesized that

\footnotetext{
${ }^{1}$ Some mothers went from for instance moderately depressed to mildly depressed, which is an improvement in the depression. However, in the study they were classified as non-improvers as they were still depressed. When re-classifying, all the results stayed the same.
} 
Table 1 Pooled means and standard deviations for main study variables by time, with and without multiple imputation

\begin{tabular}{llllll}
\hline & \multicolumn{2}{l}{ Pre-Treatment $(N=70)$} & \multicolumn{2}{l}{ Post-Treatment $(N=70)$} & \multicolumn{2}{c}{ Effect Size Cohen's $d$} \\
& $M$ & $S D$ & & $M$ & \\
Depression (mother) & 13.57 & 8.17 & 9.19 & 10.02 & .48 \\
Externalizing Behavior (child) & 72.27 & 6.38 & 66.80 & 10.22 & .64 \\
& Pre-Treatment $(N=101)$ & Post-Treatment $(N=101)$ & Effect Size Cohen's $d$ \\
Depression (mother) & $M$ & $S D$ & $M$ & $S D$ & .45 \\
Externalizing Behavior (child) & 14.08 & 9.48 & 9.76 & 9.76 & .64 \\
\hline
\end{tabular}

Means were significantly different by time, $p<.001$

maternal depression would account for some of the variability in treatment outcomes in combined PMT/CBT interventions.

The first specific objective of this study was to examine whether pre-treatment levels of maternal depression predicted treatment outcomes for children with externalizing behavior problems. Consistent with our hypothesis, the combination of PMT/CBT was found to be less effective for children of depressed mothers compared to children of nondepressed mothers. Children of non-depressed mothers showed more pronounced improvements in their externalizing behavior problems compared with children of depressed mothers. As a result of treatment, children's externalizing behavior seemed to decrease (cf. Kazdin 2005), regardless of maternal depression status. However, children of non-depressed mothers scored significantly lower than children of depressed mothers after the treatment. It is also important to note that children of depressed mothers still showed borderline clinical levels of externalizing problems after treatment, while children of non-depressed mothers were far beneath this cutoff after treatment. Although the combined PMT/CBT intervention was associated with an average decrease in externalizing behavior for the sample as a whole, the extent of improvement differed between groups according to maternal depression status, which emphasizes the role of maternal depression on child health (cf. Kahn et al. 2004). No differences were found at pre-treatment levels between children of depressed and non-depressed mothers. This was in contrast with some literature that would suggest that children of depressed mothers are at increased risk for externalizing behavior problems (e.g., Kim-Cohen et al.
2005). Although there were no differences at pre-treatment, at post-treatment significant differences in treatment outcomes did emerge when the depression status of mothers at pre-treatment was considered. These findings suggest that mothers' initial levels of impairment in terms of depressive symptomatology were associated with the likelihood that their children would benefit from treatment: those mothers who where more impaired were less likely to have children who showed low levels of externalizing behavior problems at post-treatment.

The second objective was to study the association between changes in maternal depression and changes in children's levels of externalizing behavior problems. Our hypothesis that improvements in mothers' depressive symptoms would be associated with improvements in children's externalizing behavior was not supported by the data. However, when looking at the p-values of each of the imputed datasets, five of the ten imputed datasets yielded significant results, and four of these five had a $p$-value below .01. Of the five non-significant p-values, two were marginally significant ( $p=.06$ and $p=.07$ respectively). As noted before, all the children showed the same amount of externalizing behavior before the treatment started, regardless of the depression status of their mother (depressed versus non-depressed). Although the initial levels of children's problem behavior were not different from one another, they were (marginally) significantly affected by the depression status of the mother over time (in seven out of ten datasets). In these cases, children of non-depressed mothers showed the largest decrease in externalizing behavior over time, and the children of depressed mothers who became non-depressed over the course of treatment showed the
Table 2 Pooled correlations at pre- and post-treatment for depression (mother) and externalizing behavior (child)

At pre- and post-treatment, 101 families participated $(n=101)$, $* p<.05 * * p<.01$

\begin{tabular}{lllll}
\hline & Pre-treatment & \multicolumn{2}{c}{ Post-treatment } \\
\hline Measure & Depression & Ext. Behavior & Depression & Ext. Behavior \\
Pre. Depression & - & & & \\
Pre. Ext. Behavior & $.27^{* *}$ & - & & \\
Post. Depression & $.53^{* *}$ & .19 & - & - \\
Post. Ext. Behavior & $.33^{*}$ & $.77^{* *}$ & $.28^{*}$ & - \\
\hline
\end{tabular}




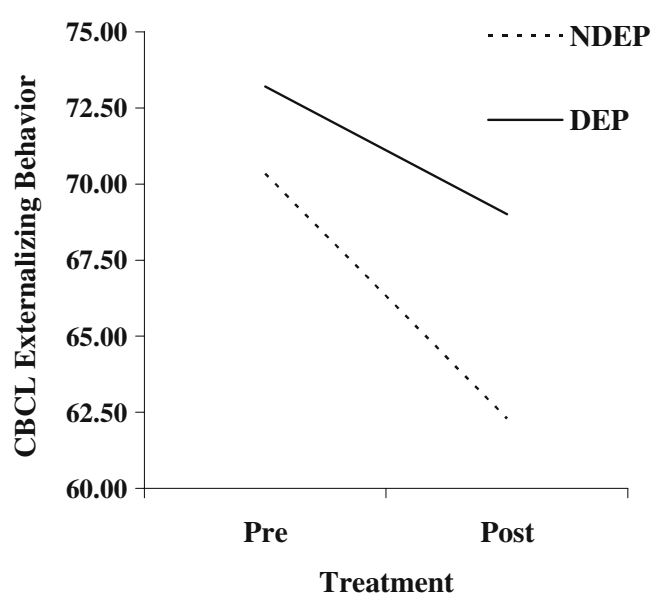

Fig. 1 Change over time in children's externalizing behavior (CBCL) according to initial levels of maternal depression (i.e. NDEP refers to non-depressed, DEP refers to depressed)

second largest decrease in their externalizing behavior moving from borderline clinical to nonclinical levels of externalizing behavior. The children of depressed mothers who remained depressed at post-treatment also showed a decrease in their externalizing behavior. However, they remained in the borderline clinical range.

The association between changes in children's problem behavior and changes in mothers' depression is particularly compelling because PMT/CBT programs do not explicitly address maternal depression (Forgatch and DeGarmo 1999). Nevertheless, it seems that features in the intervention program may have triggered improvements in mothers' moods which may, in turn, have affected children's problem behaviors (Elgar et al. 2007; McCarty and McMahon 2003). This is in accordance with the study of Scott and Stradling (1987), which examined a group of high-risk mothers and their children with parent-reported behavior problems and found a significant difference favoring the parents in the intervention group regarding improvement of their depression status. There are some potential elements of the PMT program that could have had a direct impact on parental stress and mood management. Through PMT,

Table 3 Regression model with continuous pre BDI-II scores and pre externalizing behavior scores as predictors of post externalizing behavior (Pooled results with averaged Betas) $(N=101)$

Coefficients a

\begin{tabular}{llllll}
\hline & B & SE B & $\beta$ & $\mathrm{t}$ & Sig. \\
\hline Constant & -22.06 & 8.81 & & -2.51 & 0.01 \\
Pre Ext. Behavior & 1.20 & 0.13 & 0.72 & 9.52 & 0.00 \\
Pre Depression & 0.15 & 0.12 & 0.13 & 1.28 & 0.21 \\
\hline
\end{tabular}

a. Dependent Variable: Post externalizing behavior $R^{2}=.59$

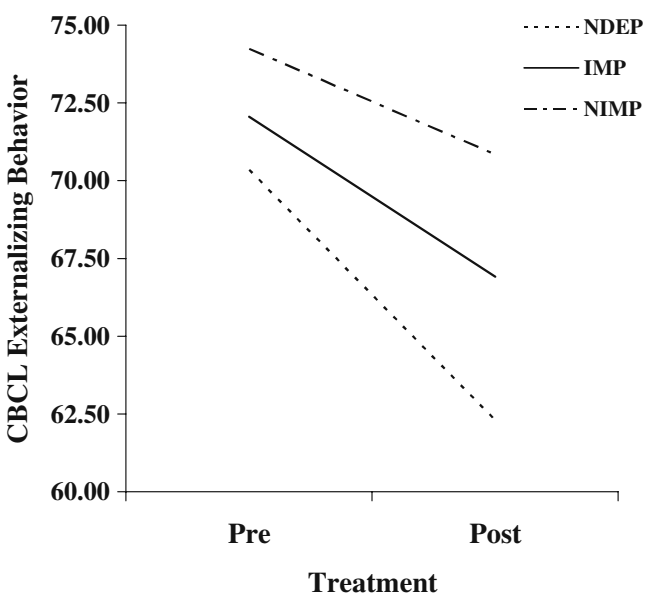

Fig. 2 Change over time in children's externalizing behavior (CBCL) according to improvement of maternal depression over time (i.e. NDEP refers to mothers who remained non-depressed, IMP refers to mothers who improved, NIMP refers to mothers who did not improve)

parents are made aware of their own anger and aggression problems and the triggers that lead them to become dysregulated. They also learn the same problem-solving strategies that are taught to the children in the child-focused CBT program and it may be argued that these strategies may indeed lead to parents' improvements in mood and decreases in levels of stress. The group format of PMT, with the opportunity for parents to commiserate, empathize and comfort one another, may be an additional reason that parents' depressive symptoms improved. Research examining the effectiveness of behavioral parenting programs in improving levels of depression is scarce and therefore future research is needed to replicate our findings. For instance, to examine the relation between parental training programs and levels of depression, a longitudinal design focusing on depressed versus non-depressed mothers and their externalizing children, randomly assigned to either a waiting list or intervention (PMT/CBT) condition, could provide insight into this matter.

There are some important limitations to the current study that future research needs to address. First, our research was conducted in partnership with community agencies to demonstrate how PMT/CBT works in "real world" settings. As a result, a randomized control trial was not feasible, rendering it difficult to demonstrate whether the treatment caused reductions in youth problems and maternal depression. Third variables such as improved communication between parents and children or changes in the school context that might have been put in place after parents became more aware of their children's struggles may have had an impact on both types of improvements. Also, similar to all clinical research in "real world" contexts, we had some attrition in terms of the relevant questionnaires being filled out, mainly at post-treatment. As a result, the sample 
size is relatively small given the heterogeneity of the sample. We attempted to impute missing data, but of course, it is possible that there was some regularity to the attrition of data and that limits the generalizability of our conclusions. Our results were significant when we used a categorical approach to measuring depression, but not when we used a dimensional one. The relative advantages of each approach have been discussed at length (e.g., Robins and McEvoy, 1990; Richters and Cicchetti 1993; Hinshaw and Anderson 1996) and there is no definitive consensus in the field regarding which strategy of assessment is best.

Another important methodological limitation is that this study was based on information from a single informant (the mothers). Mothers reported on their own levels of depression as well as their children's levels of externalizing behavior. We had attempted to gather information from teachers as well, but these data were unavailable for a significant proportion (one third) of the sample and therefore were not reliable enough to include in the present study. It is important for future research to include multiple informants to limit effects due to informant biases. But it may be that mothers are actually not as biased as previously believed. Several studies that have compared maternal reports with teachers and child self-reports have found that depressed mothers are equally accurate or even more accurate when they report on their children's behavior problems than nondepressed mothers (e.g., Conrad and Hammen 1989; Weissman et al. 1987). Beyond the issue of bias, singleinformant data is also limited because any common source of information can inflate the association between variables.

Given the concurrent data collection waves and the lack of a randomized controlled design, this study cannot comment on the direction of causality in terms of the relation between changes in maternal depression and children's behavior problems. It may be that maternal mood improved, leading to the implementation of better child management skills, which improved children's externalizing behavior. It is equally likely that improvements in children's externalizing problems led to mothers feeling more competent, in control, and perceiving their children as more pleasant, which, in turn, led to decreases in maternal depression. The direction of influence is likely bidirectional, with both these paths of influence working iteratively over the course of treatment.

More research is also needed with regard to the heterogeneity of maternal depression, as this disorder varies in its duration, severity, and recurrence (Foster et al. 2008). It is possible that mothers who are in their first depressive episode show less impaired parenting skills compared to mothers who have a long history of depression. It may be useful for future research to identify at what stage and severity the mothers are experiencing depression when they enter treatment with their children. This, in turn, could lead to more tailored interventions. For instance, cognitivebehavioral methods to gain greater control of mood are used as intervention for minor depression (Miranda and Muñoz 1994), while antidepressant pharmacotherapy is often used as intervention for major depression (Schulberg et al. 1998). Hence, whereas children of mothers with minor depressive symptoms could benefit more from treatment by adding self-control approaches to identify and change negative thoughts to PMT, children of mothers with major depressive symptoms could have more treatment success if they received antidepressants in addition to the existing intervention.

It is also important to focus on other factors that can be influential for treatment outcome for children with externalizing behavioral problems whose mothers suffer from depression (e.g., social support). Chang et al. (2007) have found that actively involved fathers can compensate for difficulties in the functioning of depressed mothers. Hence, the risk of problem behavior for children may be reduced by their father's input. Including fathers in future studies could therefore provide insight into treatment success of children with problem behavior.

Although there are some shortcomings, this study is one of the very few that has looked at changes in maternal depression in relation to children's treatment outcomes. The present study was conducted in a 'real-world' setting, which is an important contribution for the generalizability of these results. As the mothers in the present study reported on both their depressive symptoms as well as their children's externalizing behavior, the relation between improvement of maternal depression and improvement of children's externalizing behavior appeared to be a function of the combined PMT/CBT intervention. However, as a good proportion of the mothers improved their own moods, an alternative explanation could be that lower levels of depression are related to more positive perceptions of their children. Thus, it is assumed that the relation between improvement in depression and improvement in problem behavior is due to treatment, but if it is the case that only maternal perceptions changed, this still may be an important correlate to treatment effectiveness.

It was already clear that maternal depression can influence the emergence and maintenance of externalizing behavior (Elgar et al. 2004; Goodman and Gotlib 1999), but this study is one of the first to start examine the relation between maternal depression and treatment effectiveness. An implication of our study results is that more attention could be paid to maternal depression in relation to children's problem behavior as it could show better treatment outcomes. Though future research is needed, this study brought us one step further to understanding the role of maternal depression on treatment outcomes of children with externalizing behavioural problems. 
Open Access This article is distributed under the terms of the Creative Commons Attribution Noncommercial License which permits any noncommercial use, distribution, and reproduction in any medium, provided the original author(s) and source are credited.

\section{References}

Achenbach, T. M. (1991). Manual for the Child Behavior Checklist/418 and 1991 Profile. Burlington, VT: University of Vermont, Department of Psychiatry.

Barkley, R. A. (2000). Commentary on the multimodal treatment study of children with ADHD. Journal of Abnormal Child Psychology, 28, 595-599.

Barry, T. D., Dunlap, S. T., Lochman, J. E., \& Wells, K. C. (2009). Inconsistent discipline as a mediator between maternal distress and aggression in boys. Child \& Family Behavior Therapy, 31, $1-19$.

Beardslee, W. R., Versage, E. M., \& Gladstone, T. R. G. (1998). Children of affectively ill parents: a review of the past 10 years. Journal of the American Academy of Child and Adolescent Psychiatry, 37, 1134-1141.

Beck, A. T., Steer, R. A., \& Garbin, M. G. (1988). Psychometric properties of the Beck Depression Inventory: twenty-five years of evaluation. Clinical Psychology Review, 8, 77-100.

Beck, A. T., Steer, R. A., \& Brown, G. K. (1996). Manual for the Beck Depression Inventory-II. San Antonio, TX: Psychological Corporation.

Bifulco, A., Moran, P. M., Ball, C., Jacobs, C., Baines, R., Bunn, A., et al. (2002). Childhood adversity, parental vulnerability and disorder: examining inter-generational transmission of risk. Journal of Child Psychology and Psychiatry, 43, 1075-1086.

Bloomquist, M. L., \& Schnell, S. V. (2002). Helping children with aggression and conduct problems: Best practices for intervention. New York: Guildford (Xiv, 418 pp.)

Burt, K. B., Van Dulmen, M. H. M., Carlivati, J., Egeland, B., Sroufe, L. A., Forman, D. R., et al. (2005). Mediating links between maternal depression and offspring psychopathology: the importance of independent data. Journal of Child Psychology and Psychiatry, 46, 490-499.

Caughy, M. O. B., Huang, K.-Y., \& Lima, J. (2009). Patterns of conflict interaction in mother-toddler dyads: differences between depressed and non-depressed mothers. Journal of Child and Family Studies, 18(1), 10-20.

Chambless, D., \& Ollendick, T. (2000). Empirically supported therapies. Journal of Consulting and Clinical Psychology, 66, $7-18$.

Chang, J., Halpern, C. T., \& Kaufman, J. S. (2007). Maternal depressive symptoms, father's involvement, and the trajectories of child problem behaviors in a US national sample. Archives of Pediatrics and Adolescent Medicine, 161, 697-703.

Connor, D. F. (2002). Aggression and antisocial behavior in children and adolescents: research and treatment. New York: Guilford Press.

Conrad, M., \& Hammen, C. (1989). Role of maternal depression in perceptions of child maladjustment. Journal of Consulting and Clinical Psychology, 57, 663-667.

Cummings, E., Schermerhorn, A. C., Keller, P. S., \& Davies, P. T. (2008). Parental depressive symptoms, children's representations of family relationships, and child adjustment. Social Development, 17(2), 278-305.

Dumas, J. E., \& LaFreniere, P. J. (1993). Mother-child relationships as sources of support or stress: a comparison of competent, average, aggressive, and anxious dyads. Child Development, 64, 17321754.
Earlscourt Child and Family Centre. (2001a). SNAPTM children's group manual. Toronto, ON: Earlscourt Child and Family Centre.

Earlscourt Child and Family Centre. (2001b). SNAPTM parent group manual. Toronto, ON: Earlscourt Child and Family Centre.

Elgar, F. J., McGrath, P. J., Waschbusch, D. A., Stewart, S. H., \& Curtis, L. J. (2004). Mutual influences on maternal mood and child adjustment problems. Clinical Psychology Review, 24, 441459.

Elgar, F. J., Mills, R. S. L., McGrath, P. J., Waschbusch, D. A., \& Brownridge, D. A. (2007). Maternal and paternal depressive symptoms and child maladjustment: the mediating role of parental behavior. Journal of Abnormal Child Psychology, 35, 943-955.

Eyberg, S. M., Nelson, M. M., \& Boggs, S. R. (2008). Treatments for children and adolescents with disruptive behavior. Journal of Clinical Child \& Adolescent Psychology, 37, 215-237.

Fergusson, D. M., Horwood, L. J., \& Ridder, E. M. (2007). Conduct and attentional problems in childhood and adolescence and later substance use, abuse, and dependence: results of a 25-year longitudinal study. Drug and Alcohol Dependence, 88, 14-26.

Forehand, R. (1986). Parental positive reinforcement with deviant children: does it make a difference? Child and Family Behavior Therapy, 8, 19-25.

Forgatch, M. S. (1984). A two-stage analysis of family problem-solving: Global and microsocial. Doctoral dissertation, University of Oregon. Eugene, OR.

Forgatch, M. S. (1991). The clinical science vortex: Developing a theory for antisocial behavior. In D. Pepler (Ed.), The development and treatment of childhood aggression (pp. 291-315). Hillsdale, NJ: Lawrence Erlbaum.

Forgatch, M. S., \& DeGarmo, D. S. (1999). Parenting trough change: an effective prevention program for single mothers. Journal of Consulting and Clinical Psychology, 67, 711-724.

Foster, C. J. E., Garber, J., \& Durlak, J. A. (2008). Current and past maternal depression, maternal interaction behaviors, and children's externalizing and internalizing symptoms. Journal of Abnormal Child Psychology, 36, 527-537.

Gelfand, D., \& Teti, D. (1990). The effects of maternal depression on children. Clinical Psychology Review, 10, 329-353.

Goldberg, K. A., \& Leggett, E. A. (1990). Earlscourt child and family centre: Under 12 outreach project transformer club group leaders manual. Toronto, ON: Earlscourt Child and Family Centre.

Goodman, S. H., \& Brumley, H. E. (1990). Schizophrenic and depressed mothers: relational deficits in parenting. Developmental Psychology, 26, 31-39.

Goodman, S. H., \& Gotlib, I. H. (1999). Risk for psychopathology in the children of depressed mothers: a developmental model for understanding mechanisms of transmission. Psychological Review, 106, 458-490.

Hinshaw, S. P., \& Anderson, C. A. (1996). Conduct and oppositional defiant disorders. In E. J. Mash \& R. A. Barkley (Eds.), Child psychopathology (pp. 113-149). New York: Guilford.

Hirshfeld-Becker, D. R., Petty, C., Micco, J. A., Hening, A., Park, J., Beilin, A., et al. (2008). Disruptive behavior disorders in offspring of parents with major depression: association with parental behavior disorders. Journal of Affective Disorders, 111, $176-184$.

Huesman, L. R., Eron, L. D., \& Dubow, E. F. (2002). Childhood predictors of adult criminality: are all risk factors reflected in childhood aggressiveness? Criminal Behavior and Mental Health, 12, 185-208.

Jacob, T., \& Johnson, S. L. (2001). Sequential interactions in the parent-child communications of depressed fathers and depressed mothers. Journal of Family Psychology, 15(1), 38-52.

Johnson, J. G., Cohen, P., Kasen, S., Smailes, E., \& Brook, J. S. (2001). Association of maladaptive parental behavior with 
psychiatric disorder among parents and their offspring. Archives of General Psychiatry, 58, 453-460.

Kahn, R. S., Brandt, D., \& Whitaker, R. C. (2004). Combined effect of mothers' and fathers' mental health symptoms on children's behavioral and emotional well-being. Archives of Pediatrics and Adolescent Medicine, 158, 721-729.

Kazdin, A. E. (2005). Parent management training: Treatment for oppositional, aggressive, and antisocial behavior in children and adolescents. New York: Oxford Univiversity Press.

Kim-Cohen, J., Moffitt, T. E., Taylor, A., Pawlby, S. J., \& Caspi, A. (2005). Maternal depression and children's antisocial behavior: nature and nurture effects. Archives of General Psychiatry, 62, 173-181.

Lovejoy, M. C., Graczyk, P. A., O'Hare, E., \& Neuman, G. (2000). Maternal depression and parenting behavior: a meta-analytic review. Clinical Psychology Review, 20, 561-592.

Martinez, C. R., Jr., \& Forgatch, M. S. (2001). Preventing problems with boys' noncompliance: effects of a parent training intervention for divorcing mothers. Journal of Consulting and Clinical Psychology, 69, 416-428.

McCart, M. R., Priester, P. E., Davies, W. H., \& Azen, R. (2006). Differential effectiveness of behavioral parent-training and cognitive-behavioral therapy for antisocial youth: a metaanalysis. Journal of Abnormal Child Psychology, 34, 527-543.

McCarty, C. A., \& McMahon, R. J. (2003). Mediators of the relation between maternal depressive symptoms and child internalizing and disruptive behavior disorders. Journal of Family Psychology, $17,545-556$

Miranda, J., \& Muñoz, R. (1994). Intervention for minor depression in primary care patients. Psychosomatic Medicine, 56, 136-142.

Moore, K. J., \& Patterson, G. R. (2009). Parent training. In J. E. Fisher (Ed.), General principles and empirically supported techniques of cognitive behavior therapy (pp. 481-487). Hoboken, NJ, US: John Wiley \& Sons Inc. US.

Pardini, D. A., Barry, T. D., Barth, J. M., Lochman, J. E., \& Wells, K. C. (2006). Self-perceived social acceptance and peer social standing in children with aggressive-disruptive behaviors. Social Development, 15, 46-54.

Patterson, G. R. (1982). Coercive family processes. Eugene, OR: Castalia.

Patterson, G. R., Reid, J. B., \& Dishion, T. J. (1992). Antisocial boys. Eugene, OR: Castalia.

Patterson, G. R., Dishion, T. J., \& Chamberlain, P. (1993). Outcomes and methodological issues relating to treatment of antisocial children. In T. R. Giles (Ed.), Handbook of effective psychotherapy. New York: Plenum.

Richter, P., Werner, J., Heerlein, A., Kraus, A., \& Sauer, H. (1998). On the validity of the Beck Depression Inventory: a review. Psychopathology, 31, 160-168.

Richters, J. E., \& Cicchetti, D. (1993). Mark Twain meets DSM-111$\mathrm{R}$ : conduct disorder, development, and the concept of harmful dysfunction. Development and Psychopathology, 5, 5-29.

Robins, I..N., \& McEvoy, L. (1990). Conduct problems as predictors of substance abuse. In L.N. Robins \& M. Rutter (Eds.), Straight and Devious Pathways from Childhood to Adulthood (pp. 182204).

Rubin, D. B. (2004). Multiple imputation for nonresponse in surveys. Reprinted with editorial corrections and new appendices as a "Wiley Classic.". New York: Wiley.

Schulberg, H. C., Katon, W., Simon, G. E., \& Rush, A. J. (1998). Treating major depression in primary care practice: an update for the Agency for Health Care Policy and research practice guidelines. Archives of General Psychiatry, 55, 1121-1127.

Scott, M. J., \& Stradling, S. G. (1987). Evaluation of a group programme for parents of problem children. Behavioral psychotherapy, 15, 224-239.

Snyder, J., \& Patterson, G. R. (1995). Individual differences in social aggression: a test of a reinforcement model of socialization in the natural environment. Behavior Therapy, 26, 371-391.

Teti, D. M., \& Gelfand, D. M. (1997). Maternal cognitions as mediators of child outcomes in the context of postpartum depression. In L. Murray \& P. Cooper (Eds.), Postpartum depression and child development. London: Guilford Press.

Weissman, M. M., Wickramatratne, P., Warner, V., John, B. A., Prusoff, A., Merikangas, K. R., et al. (1987). Assessing psychiatric disorders in children: discrepancies between mothers ${ }^{1}$ and childrens ${ }^{1}$ reports. Archives of General Psychiatry, 44, 747-753.

Weissman, M. M., Pilowsky, D. J., Wickramaratne, P. J., Talati, A., Wisniewski, S. R., Fava, M., et al. (2006). Remissions in maternal depression and child psychopathology: a STAR*Dchild report. Journal of the American Medical Association, 295, $1389-1398$.

Wickramaratne, P. J., \& Weissman, M. M. (1998). Onset of psychopathology in offspring by developmental phase and parental depression. Journal of the American Academy of Child and Adolescent Psychiatry, 37, 933-942. 